\title{
Multiple immuno-regulatory defects in type-1 diabetes
}

\author{
Anjli Kukreja, ${ }^{1}$ Giulia Cost, ${ }^{1}$ John Marker, ${ }^{1}$ Chenhui Zhang, ${ }^{1}$ Zhong Sun,${ }^{1}$ Karen Lin-Su, ${ }^{1}$ \\ Svetlana Ten, ${ }^{1}$ Maureen Sanz, ${ }^{1}$ Mark Exley, ${ }^{2}$ Brian Wilson, ${ }^{3}$ Steven Porcelli, ${ }^{4}$ \\ and Noel Maclaren ${ }^{1}$
}

${ }^{1}$ Department of Pediatrics, Weill College of Medicine of Cornell University, New York, New York, USA

${ }^{2}$ Cancer Biology Program, Hematology-Oncology Division, Department of Medicine, Beth Israel Deaconess Medical Center and Harvard Medical School, Boston, Massachusetts, USA

${ }^{3}$ Cancer Immunology and AIDS Program, Dana Farber Cancer Institute, Boston, Massachusetts, USA

${ }^{4}$ Department of Microbiology and Immunology, Albert Einstein College of Medicine, Bronx, New York, USA

Address correspondence to: Noel Maclaren, Department of Pediatrics, Weill College of Medicine of Cornell University, LC-623 1300 York Avenue, New York, New York 10021, USA.

Phone: (212) 746-1894; Fax: (212) 746-1185; E-mail: nkmaclaren@aol.com.

Received for publication June 22, 2001, and accepted in revised form October 29, 2001.

Susceptibility to immune-mediated diabetes (IMD) in humans and NOD mice involves their inherently defective $\mathrm{T}$ cell immunoregulatory abilities. We have followed natural killer (NK) $\mathrm{T}$ cell numbers in patients with IMD, both by flow cytometry using mAbs to the characteristic junctions found in the $\mathrm{T}$ cell receptors of this cell subtype, and by semiquantitative RT-PCR for the corresponding transcripts. Both before and after clinical onset, the representation of these cells in patients' PBMCs is reduced. We also report low numbers of resting $\mathrm{CD} 4^{+} \mathrm{CD} 25^{+} \mathrm{T}$ cells in IMD patients, a subset of $\mathrm{T}$ cells shown to have important immunoregulatory functions in abrogating autoimmunities in 3 -day thymectomized experimental mice. Whereas a biased Th1 to Th2 cytokine profile has been suggested to underlie the pathogenesis of IMD in both species, we found defective production of IFN- $\gamma$ in our patients after in vitro stimulation of their PBMCs by phorbol-myristate acetate and ionomycin and both IFN- $\gamma$ and IL-4 deficiencies in $\mathrm{V} \alpha 24^{+} \mathrm{NK}$ T-enriched cells. These data suggest that multiple immunoregulatory $\mathrm{T}$ (Treg) cell defects underlie islet cell autoimmunity leading to IMD in humans and that these lesions may be part of a broad $\mathrm{T}$ cell defect.

J. Clin. Invest. 109:131-140 (2002). DOI:10.1172/JCI200213605.

\section{Introduction}

Immune-mediated (type 1) diabetes (IMD) is an incurable disease of children and adults that is increasing in incidence throughout the Western world (1). It results from chronic autoimmune destruction of pancreatic $\beta$ cells in individuals who are genetically prone to IMD through having multiple weak susceptibility genes in the absence of protective genes, with penetrances that are strongly influenced by the environment. The discovery of Th1 and Th2 subsets has helped to explain the immunological basis for the diversity of $\mathrm{T}$ cell responses in autoimmune diseases such as IMD (2). Destruction of pancreatic $\beta$ cells in humans and nonobese diabetic (NOD) mice is mediated through cellular immune mechanisms and a biased Th1 immune pathway. Various studies in NOD mice have shown that $\beta$ cell destruction is observed in conjunction with infiltration of local IFN $-\gamma^{+} \mathrm{T}$ cells (3), while experimentally induced lesions dominated by IL-4-producing $\mathrm{T}$ cells are generally benign to or even protect against islet cell destruction (4). Diabetes is transferable from NOD mice by $\mathrm{CD}^{+} \mathrm{T}$ cells that express Th1 cytokines, while treatments with rIL-4 or rIL-10 have been shown to protect them from diabetes (5). Like NOD mice, a Th1-dominated infiltration of T cells into the islets (insulitis) has also been observed in type 1 diabetic patients (6), suggesting that they too have an underlying Th1 bias $(3,7)$. However, the respective contributions of Th1 and Th2 cytokines to the pathogenesis of IMD remain controversial, with reports showing that diabetes development in NOD mice may not require IFN- $\gamma$ signaling $(8,9)$ and can be accelerated by the transgenic expression of IL-10 in pancreatic $\beta$ cells (10). In humans, Halminen et al. (11) recently studied the expression profile of mRNAs of IFN- $\gamma$ and IL-4 in resting blood and found them both to be significantly reduced in newly diagnosed diabetic patients as compared with normal controls.

Both central and peripheral tolerance mechanisms may be compromised in newly diagnosed IMD patients and NOD mice. Clonal deletion of autoreactive $T$ cells in the thymus is one mechanism for the induction of tolerance to self-antigens. This may involve diminished expression of insulin in the thymus of individuals with the protective genomic VNTR alleles $5^{\prime}$ to the insulin gene. Others have suggested that it is the ineffective antigenic binding to IMD-prone HLA-DQ or-DR that promotes islet cell autoimmunity, since this permits autoreactive $\mathrm{T}$ cells to escape thymic ablation and pass into the circulation.

However, defective apoptosis of activated $\mathrm{T}$ cells have been reported in animal models of diabetes (12) and 
associations with CTLA-4 polymorphisms in type 1 diabetic patients, especially of Spanish descent (13), are two observations that could explain breaches in peripheral tolerance. $T$ regulatory (Treg) cells are involved in almost all experimental animal models of autoimmunity, and natural killer (NK) T cells and resting $\mathrm{CD} 4^{+} \mathrm{CD} 25^{+} \mathrm{T}$ cells have emerged as important immunoregulatory $\mathrm{T}$ cell subsets. Importantly, reconstitution of animal models by populations of Treg cells has been shown to prevent the development of autoimmunity.

Whereas NK T cells have powerful antitumor effects, mediating their cytotoxicity by an NK-like effector mechanism that is IL-12 dependent $(14,15)$, they also serve as regulators that secrete IL-4 and IL-13, and pro-Th2 factors that inhibit Th1-mediated cytotoxic $\mathrm{T}$ lymphocyte (CTL) responses (16). NK T cells are either $\mathrm{CD}^{+}(17)$ or CD4-CD8- double negative (DN) (18) and have a highly conserved TCR repertoire $(19,20)$. They are CD1d responsive to antigen presented to them by dendritic cells (DCs), but are not HLA restricted. The CD1d binding cleft is hydrophobic, binding and presenting glycolipid rather than peptide antigens to responding NK T cells. They express an invariant TCR $\alpha$ chain composed of variable gene repertoire V $\alpha 14$ and J $\alpha 281$ segments in mice or $V \alpha 24$ and $J \alpha Q$ segments in humans, indicating a highly conserved antigenic specificity, albeit their natural ligand has not yet been identified. These subsets are also highly biased toward $\mathrm{V} \beta 8.2, \mathrm{~V} \beta 7$, and $\mathrm{V} \beta 2$ usage in mice and V $\beta 11$ in humans. Both $\mathrm{CD}^{+}$and DN NK T cell subsets produce high levels of IFN- $\gamma$ and IL- 4 when stimulated (21). Disturbances in numbers and functions of NK T cells have been implicated in several organ-specific animal models of autoimmunity as well as in humans, although in some of these studies it is unclear whether the changes reflect a cause or effect of disease. Mieza et al. showed that murine $\mathrm{V} \alpha 14^{+} \mathrm{T}$ cells were specifically reduced with aging in C57BL/6 lpr/lpr or MRL $l p r / l p r$ mice, whereas no age-related changes were observed in control mice (22). Mice prone to experimental allergic encephalomyelitis, a T cell-mediated autoimmune disease like IMD, have serious functional defects of NK T cells (23). Various studies in NOD mice have suggested that these mice are deficient and/or functionally defective in NK T cells and that diabetes can be prevented by adoptive transfer of NK T cell-enriched DN cells (24-26). Similarly, human studies have suggested that NK T cell deficiencies are associated with various $T$ cell-mediated autoimmune diseases (27-29).

NK T cells with their invariant TCR are not the only population of Treg cells, since $\mathrm{T}$ cells with diverse TCRs expand in autologous mixed lymphocytic reactions and mediate antigen-specific suppressor activity. $\mathrm{CD} 4^{+} \mathrm{CD} 25^{+} \mathrm{T}$ cells are a unique population of Treg cells in that when otherwise normal mice made deficient by 3-day thymectomies, they develop organ-specific autoimmunities, which are preventable by transfer of $\mathrm{CD} 4^{+} / \mathrm{CD} 25^{+} \mathrm{T}$ cells $(30)$. CD $4^{+} \mathrm{CD} 25^{+} \mathrm{T}$ cells in normal mice thus represent a distinct lineage of "professional" suppressor cells (31) thought to act through direct contact with responder cells rather than through released cytokines (32). Previous studies have shown that prior elimination of this $\mathrm{CD} 4^{+} \mathrm{T}$ cell subset from splenocytes by Ab's to CD25 (5-10\% of peripheral $\mathrm{CD}^{+} \mathrm{T}$ cells) makes these cells potent inducers of autoimmunity when injected into nude mice (33). However, little information was available on this subpopulation in humans until recently. Stephens et al. (34) showed that this subset of Treg cells in human thymus and periphery mediates immunoregulatory effects through direct cell contacts. These human cells behave very similarly to those described in mice by expressing CTLA- 4 constitutively, by becoming anergic in the absence of exogenous IL-2, and by suppressing the activation of $\mathrm{CD} 4^{+} \mathrm{CD} 25^{-}$cells in vitro. As a consequence, we studied the $\mathrm{CD} 4^{+} / \mathrm{CD} 25^{+}$ subset as well as NK T cells in IMD patients to explore their possible roles in the disease.

Here we report that in spontaneous IMD of humans, regulatory/suppressor $\mathrm{T}$ (Treg) cells are markedly reduced in numbers, and peripheral $\mathrm{T}$ cells are defective in secreting Th1 (IFN- $\gamma$ ) cytokine, suggesting some broad underlying intrinsic $T$ cell defects of which defective Treg cells ( $\mathrm{NK} \mathrm{T}$ and $\mathrm{CD} 4^{+} \mathrm{CD} 25^{+} \mathrm{T}$ cells) are a part.

\section{Methods}

Patients. All 54 type 1 diabetic study patients fulfilled the diagnostic criteria in that they presented with sustained hyperglycemia, proneness to develop ketoacidosis, polyuria, polydipsia, weight loss, and symptoms consistent with underlying insulinopenia. The diagnosis of IMD was confirmed by the presence of cytoplasmic islet cell autoantibodies (ICA), and/or autoantibodies to glutamic acid decarboxylase $\left(\mathrm{GAD}_{65} \mathrm{~A}\right)$, and/or to the tyrosine phosphatase insulinoma antigen-2 (IA-2A), and/or to insulin (IAA). Blood samples were collected from 31 newly diagnosed diabetic patients within 3 months of their diagnosis and from 23 long-established patients who have had diabetes for $8.7 \pm 7.0$ years. We studied 12 nondiabetic relatives of such patients who were at risk of impending diabetes because they had one or more positive ICAs. We also studied 15 type 2 diabetic patients as diabetic controls. These latter patients had strong family histories of type 2 diabetes, were overweight (body mass indices greater than 27), and all but one had acanthosis nigricans. Blood samples were also obtained from 26 normoglycemic volunteer controls under protocols approved by Weill/Cornell-New York Hospital institutional review board (Table 1). Fresh PBMCs were isolated on Ficoll density gradients and analyzed within hours of sampling in all cases.

$A b$ 's and reagents. The following Ab's from Coulter Immunotech (Miami, Florida, USA) were used in our studies: IgG1 (679.1Mc7), IgG2a (U7.27), anti-V $\alpha 24$ (C15), anti-Vß11 (C21), and anti-human CD25 (B1.49.9). Anti-CD3 (UCHT-1), anti-CD4 (Q4120), and anti-CD8 (UCHT-4) were purchased from Sigma Chemical Co. (St. Louis, Missouri, USA). Ab's to the cytokines 
IFN- $\gamma$ and IL-4 were purchased from PharMingen (San Diego, California, USA). The mAb (6B11) to the invariant $V \alpha 24 J \alpha Q$ junction used in our studies was developed by B. Wilson and M. Exley as follows.

Briefly, cyclic peptides representing the CDR3 loop of the invariant TCR- $\alpha$ sequence acetylCVVSDRGTLGRLADCG with C at P15 were linked to the acetyl methylene group by a thioether linkage. This construct left the sulfhydryl of the $\mathrm{C}$ residue available for coupling to $\mathrm{N}$-ethylmaleimide-activated keyhole limpet hemocyanin (KLH), BSA, or ovalbumin. The cyclic peptide was coupled to activated KLH for immunization, to BSA to boost the response, and to ovalbumin to screen hybridomas, as recommended by the manufacturer (Pierce Chemical Co., Rockford, Illinois, USA). One hundred and twenty-nine C57BL/6 F2 CD1d knockout (KO) mice (35) were immunized intraperitoneally and subcutaneously with invariant peptide-KLH and CFA, boosted 4 weeks later with invariant peptide-BSA and IFA, and reboosted intravenously 10 days later, $4-5$ days prior to hybridoma fusion, with either invariant peptide-BSA or a DN2.D6 invariant NK T cell clone (18). Following fusion with NS0 myeloma by conventional means, each hybridoma was screened by ELISA on invariant peptideovalbumin, and those determined to be positive were counter-screened against ovalbumin alone.

Hybridomas secreting Ab's reactive with invariant peptide were screened for reactivity against the DN2.D625 and other invariant NK T cell clones and for reactivity against control unrelated $\mathrm{T}$ cell clones by indirect FACS using anti-IgG FITC as described (18). Briefly, $10^{6}$ cells were suspended in FACS buffer (PBS, FBS 1\%, and NaN3 0.1\%) in a 96-well plate. Nonspecific binding was blocked by preincubating with $10 \%$ human serum for 15 minutes. Ab's were added to cell suspensions for 20 minutes. Cells were then washed with FACS buffer, incubated with anti-murine immunoglobulin (anti-mIg), FITC (Pierce Chemical Co.), rewashed, and analyzed by FACScan (Becton Dickinson Immunocytometry Systems, San Diego, California, USA), using CellQuest Software.

Ab's specifically reactive with invariant NK T cell clones were tested for reactivity against PBMCs and polyclonal invariant NK T cell lines. Two mAb's in particular were carried further since they clearly reacted specifically with all invariant NK T cells tested. These were 6B11 (IgG1) and $3 \mathrm{~A} 6(\mathrm{IgM})$. The former $\mathrm{mAb}$ was used in our studies.
Phenotypic and functional analysis of human $T$ cells. Peripheral blood lymphocytes were analyzed by flow cytometery using a FACScalibur (Becton Dickinson Immunocytometry Systems). Immunofluorescence staining was performed using specific mAbs according to standard procedures. For enumeration of NK T cells, at least 200,000 events were analyzed. Cytokine production (IFN- $\gamma$ and IL-4) was assessed by flow cytometry on phorbol myristate acetate and calcium ionomycin-activated (PMA + I-activated) cells. PBMCs $\left(10^{6} /\right.$ well) were stimulated in 96 -well round-bottom plates for 5 hours with PMA (Sigma Chemical Co) at 50 $\mathrm{ng} / \mathrm{ml}$ and I (Sigma Chemical Co.) at $1-\mu \mathrm{M}$ concentrations. Detection of intracellular cytokines was optimized, by activating the cells in the presence of $3 \mu \mathrm{M}$ monensin (PharMingen), which prevents cytokine secretion and thus allows their intracytoplasmic accumulation. Unstimulated control wells were incubated with monensin alone. Cells were fixed with $4 \%$ paraformaldehyde at the end of a 5-hour incubation period and were permeabilized with Perm/Wash solution containing saponin (PharMingen) to allow $\mathrm{Ab}$ access for staining of IFN- $\gamma$ and IL-4.

Isolation of $C D 4^{-} C D 8^{-} D N T$ cells. T cells were separated from PBMCs using a pan-T cell isolation kit (Miltenyi Biotec, Auburn, California, USA). DN T cells were obtained from PBMCs by negative selection using $\mathrm{CD}^{+}$and $\mathrm{CD}^{+}$microbeads (Miltenyi Biotech).

Molecular analysis of canonical $V \alpha 24 J \alpha Q$ transcripts. A Southern blot technique was used to identify the Vo24J $\alpha Q$ TCR chain among the PCR-amplified Vo24-C $\alpha$ clonotypes. Total RNA was extracted from PBMCs and DN T cells using Trizol (Invitrogen, Carlsbad, California, USA), and $2 \mu \mathrm{g}$ was reverse transcribed using an outer primer of the constant region of the TCR- $\alpha\left(5^{\prime}\right.$ ATACACATCAGAATTCTTACTTTG $\left.3^{\prime}\right)$ and of the HPRT gene ( $5^{\prime}$ AGGGAACTGCTGACAAAGATTC $\left.3^{\prime}\right)$. First-round RT-PCR was performed on the transcribed cDNA using an outer primer of the variable region of the canonical TCR Vo24 (5' TATACAGCAACTCTGGAT $3^{\prime}$ ) in a thermal cycler GeneAmp PCR System 9700 for 30 cycles $\left(60\right.$ seconds at $94^{\circ} \mathrm{C}, 60$ seconds at $50^{\circ} \mathrm{C}$, and 60 seconds at $72^{\circ} \mathrm{C}$ ). The second round of PCR was performed using the inner primer pair (sense 5' AAGCAAAGCTCTCTGCACATCACA $3^{\prime}$ and antisense $5^{\prime}$ GTCACTGGatTTAGAGTCT $3^{\prime}$ ) under the conditions identical to those of the first round of PCR. The sam-

Table 1

Patients demographics

\begin{tabular}{|c|c|c|c|c|c|c|}
\hline Groups & Total number of subjects & Male/female & Mean age (years) $\pm S D$ & $\mathrm{ICA}^{+} / \mathrm{ICA}^{-}$ & $\mathrm{GAD}_{65} \mathrm{~A}^{\mathrm{A}}$ & $I A-2 A^{B}$ \\
\hline Normal controls & 26 & $12 / 14$ & $37 \pm 5.66$ & $0 / 25$ & $0 / 25$ & $0 / 25$ \\
\hline $\mathrm{ICA}^{+}$relatives & 12 & $5 / 7$ & $15.82 \pm 11.44$ & $12 / 0$ & $7 / 12$ & $5 / 12$ \\
\hline Newly diagnosed type 1 diabetics & 31 & $17 / 14$ & $9.4 \pm 2.16$ & $28 / 3$ & $8 / 31$ & $13 / 31$ \\
\hline Long-standing type 1 diabetics & 23 & $12 / 11$ & $\begin{array}{c}45.2 \pm 9.7 \\
\text { (Duration } 8.7+7.0 \text { years) }\end{array}$ & $14 / 9$ & $8 / 23$ & $4 / 23$ \\
\hline Type 2 diabetics & 15 & $2 / 13$ & $35.35 \pm 19.63$ & $0 / 14$ & $0 / 14$ & $0 / 14$ \\
\hline
\end{tabular}

AGlutamic acid decarboxylase autoantibodies. ${ }^{B}$ Insulinoma-associated tyrosine phosphatase-like protein-2 autoantibodies. 

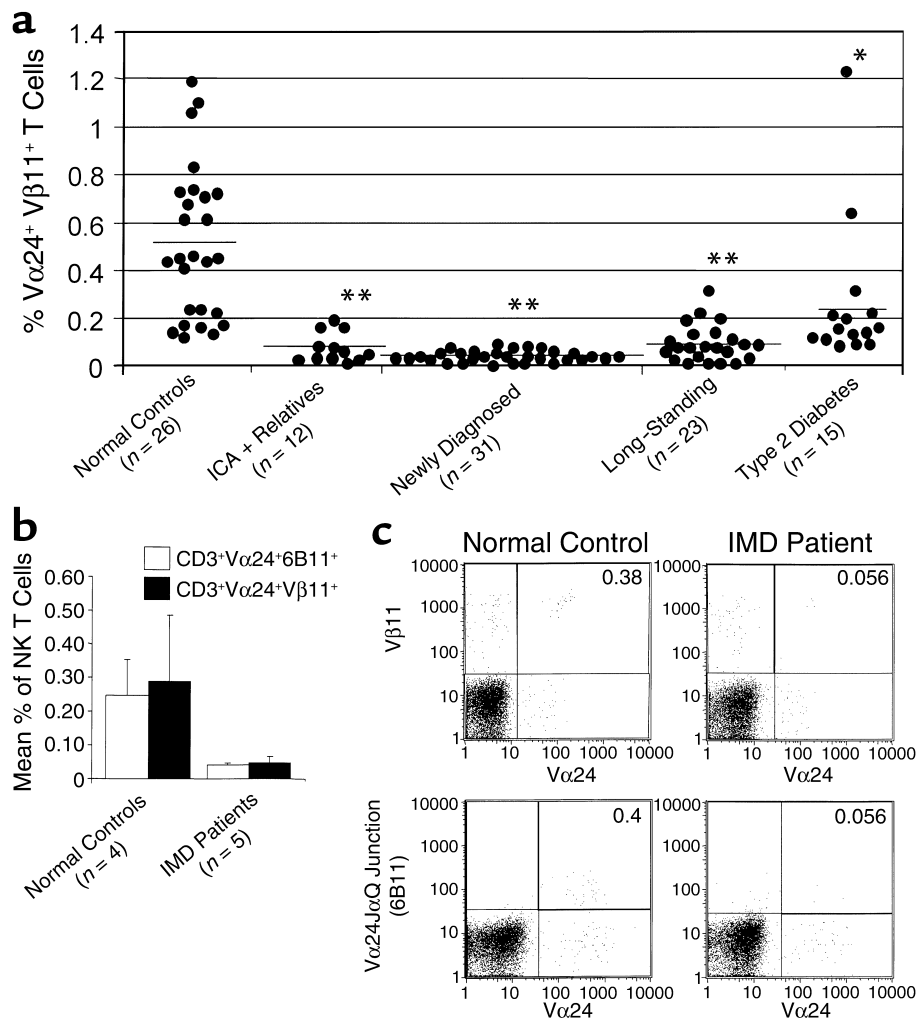

\section{Figure 1}

NK T cell defect in IMD patients. (a) NK T cells in the peripheral blood were characterized by a three-color flow cytometry assay using $\mathrm{mAbs}$ to $\mathrm{CD} 3$ and to receptors bearing expressed $V \alpha 24$ and $V \beta 11$. The triple-positive population $\left(C D 3^{+} V \alpha 24^{+} V \beta 11^{+}\right)$showed marked reductions in both newly diagnosed $(P<0.0001)$ and long-term immune-mediated diabetic patients $(P<0.007)$ compared with controls. Nine multi-autoantibody-positive relatives of the 12 patients studied similarly had significantly reduced numbers of triple-positive cells $(P<0.0001)$. Whereas the type 2 diabetic patients also had lower levels than controls $(P<0.02)$, their deficiency was less marked than the IMD patients $(P<0.04)$. The horizontal lines represent means; $n$ is the number of subjects in each group. (b) Comparisons are shown between NKT cells as defined by staining with $C D 3, V \alpha 24$, and $m A b$ to the $V \alpha 24 J \alpha Q$ junction (6B11) to NK T cells defined by staining with $\mathrm{CD} 3^{+} \mathrm{V} \alpha 24^{+} \mathrm{V} \alpha 11^{+} \mathrm{mAbs}$ in patient and control groups. No differences were found in the NKT cell numbers as stained by the two different sets of mAbs. (c) A dot plot comparing the measurement of NKT cells using $V \alpha 24$ and $V \beta 11$ $m A b s$ and $V \alpha 24$ and the invariant J $\alpha Q$ junction $m A b$ (6B11) in a representative normal control and a newly diagnosed IMD patient are shown. The patient has reduced doubly stained cells (upper-right quadrants) using either sets of mAbs. ${ }^{*} P<0.007,{ }^{*} P<0.04$. ples were then loaded onto a $2 \%$ agarose gel. After electrophoresis, the DNA was transferred to a nylon membrane (Hybond $-\mathrm{N})$ and was hybridized with $\left[\gamma^{-32} \mathrm{P}\right]$ ATP-labeled J $\alpha \mathrm{Q}$ probe $\left(5^{\prime}\right.$ ACTCAGTTGACTGTCTGGCCTGAT $\left.3^{\prime}\right)$. The filter was prehybridized at $65^{\circ} \mathrm{C}$ overnight in buffer followed by overnight hybridization at $50^{\circ} \mathrm{C}$ in the presence of ${ }^{32} \mathrm{P}$-labeled J $\alpha \mathrm{Q}$ probe. The membrane was later washed in $2 \times, 1 \times$, and $0.5 \times$ SSC for 20 minutes at $55^{\circ} \mathrm{C}$ and was subsequently autoradiographed. The PCR products were quantified using phosphorimaging.

Similarly, PCR was performed using HPRT primers (sense $5^{\prime}$ GTCGTGATTAGTGATGATGAAACCAGGTTATGACC $3^{\prime}$ and antisense $5^{\prime}$ CACCAGCAAGCTTGCGACCTTG $3^{\prime}$ ), and the PCR product (474 bp) was hybridized with $\left[\gamma^{-32} \mathrm{P}\right]$ ATP-labeled HPRT probe (5' GCCATCACATTGTAGCCCTCTG $3^{\prime}$ ).

CD1d sequencing. The human $\mathrm{CD} 1 \mathrm{~d}$ gene mutation study was carried out using an ABI 377 automatic sequencer. Primer pairs covering the whole $\mathrm{CD} 1 \mathrm{~d}$ gene were designed based on the sequence of $\mathrm{CD} 1 \mathrm{~d}$ gene (accession number X14974). Genomic DNA (10 ng) from both patients and normal controls used as a template was amplified by appropriate primer pairs using Taq DNA polymerase in a $50-\mu \mathrm{l}$ reaction volume under standard reaction conditions. The PCR products were precipitated twice by isopropanol/ethanol and dissolved in $25 \mu \mathrm{l}$ $\mathrm{H}_{2} \mathrm{O}$. Two microliters of the dissolved PCR products were then used as a template DNA for each sequencing reaction following the applied biosystems inherit protocol. Sequence data of each patient and normal control was compared with the reference sequence of CD1d in the gene bank (GenBank National Center for the National Library of Medicine Biotechnical Information, NIH, Bethesda, Maryland, USA) by Sequencer software.

All six exons of CD1d gene were PCR amplified using primers that flanked each exon as shown below:

exon 1: forward primer GAATTGGCTGGCACCCAGCGGAAAG, reverse primer CGAGTTTTCTACCTAGATCGCG; exon 2: forward primer CCACTTGCTACACGCCTCCAATC, reverse primer CCAGTTGAGTTTCTGTGGCCATTC; exon 3: forward primer CTCAAATGTCCCTCGTTCCTGC, reverse primer GCTCAAAGGGATGAGAACCCTGG; exon 4: forward primer CCAGAAGTGAACATGTCAGG, reverse primer CCTCCTGCCATTTCCAGCTTGG; exon 5 and 6 : forward primer GTACCCTCACACATGCCTAGAC, reverse primer CTTGGGAACCTGAGGTCCAGAG.

In addition, the $1.8 \mathrm{-kb}$ upstream regulatory region of CD1d gene was also screened for mutations by PCRbased sequencing analysis. We designed three sets of primer pairs, test, $t$, each covering an interval of around 600 bases in this region.

Promoter region 1: forward primer GATAGGCTGGGTTAGGGCTG, reverse primer CAAGATTATGCGCCCTCTAGC; promoter region 2: forward primer GATGCTGGGGTGTGAGGTGATG, reverse primer CTGGATTAGGTTGGCTAC; promoter region 3: forward primer GAATCCTGGGATATGACAGTTG, reverse primer CTCTGACCTGCGCACTCTTCT.

Statistical analysis. Differences between mean values were evaluated by two-sided Student $t$ test, with a level of significance set as $P$ values less than 0.05 . 


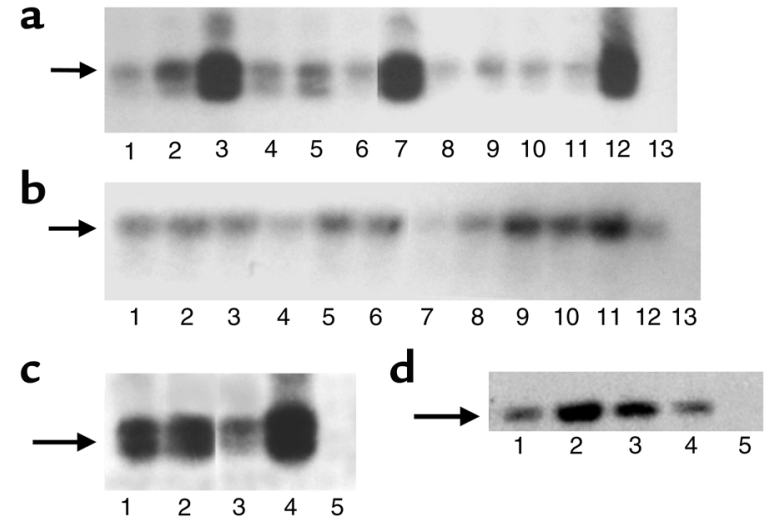

e

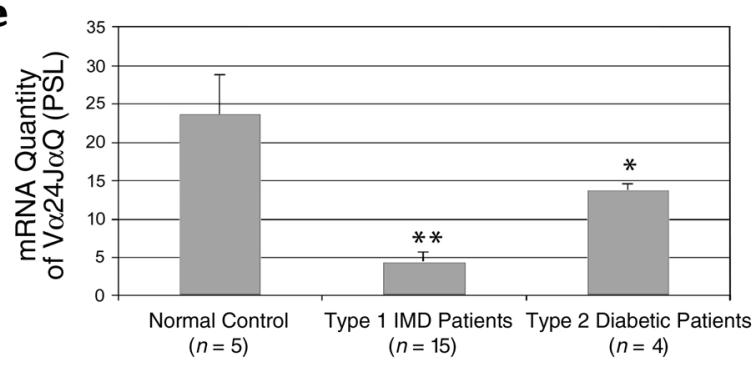

Figure 2

PBMC and CD4-CD8- DN T cells from patients and normal controls were examined for $V \alpha 24 J \alpha Q$ expression by the Southern blot technique. (a and c) V $\alpha 24 J \alpha Q$ TCR transcripts are shown. (b and d) For the housekeeping gene HPRT expressions in the same subjects. (a) Expression of $V \alpha 24 \mathrm{~J} \alpha \mathrm{Q}$ mRNA in the peripheral blood of IMD patients (lanes $1,2,4,5,6,9,10$, and 11) are compared with normal controls (lanes 3 and 12). Lanes 7 and 8 compare the TCR expression in the DN population between controls and patients, respectively. Lane 13 is the negative control. (c) This figure part compares the expression of canonical $V \alpha 24 \mathrm{~J} \alpha \mathrm{Q}$ transcripts in the patients with type 2 diabetes (lanes 1, 2, and 3 ) with a normal control (lane 4). Lane 5 is the negative control. The arrows indicate the position of the invariant $V \alpha 24 J \alpha Q$ and HPRT bands. (e) The relative expression intensities of the canonical $V \alpha 24 J \alpha Q T C R$ as normalized to HPRT gene expression in controls, IMD patients, and patients with type 2 diabetes are shown. The mRNA levels were all determined by RT-PCR followed by quantification of radiolabel by phosphorimaging. Shown in e are the mean levels of $\mathrm{V} \alpha 24 \mathrm{~J} \alpha \mathrm{Q}$ calibrated to the amount of HPRT gene expression in the sample. The bars indicate means plus $1 \mathrm{SE}$. Significant differences from the normal control group are ${ }^{*} P<0.05$ and ${ }^{*} P<0.01$.

\begin{abstract}
Results
Phenotypic and molecular characterization of NK T cells in the peripheral blood of patients with IMD. All 31 newly diagnosed IMD (28 were ICA ${ }^{+}$) and 14 of the 23 long-standing type 1 diabetic patients were positive for one or more islet autoantibodies when studied. Conversely, none of the 26 controls or the 15 type 2 diabetic patients had any ICAs. Detailed patient demographics and autoantibodies identified, including the $12 \mathrm{Ab}-$ positive but nondiabetic persons, are shown in Table 1.

NK T cells represent only approximately $1 \%$ of the normal PBMC population. Cell surface phenotype analyses of PBMCs using mAbs to encompass the human NK $\mathrm{T}$ cell subset $\left(\mathrm{CD}^{+}, \mathrm{V} \alpha 24^{+}\right.$, and $\left.\mathrm{V} \beta 11^{+} \mathrm{TCR}\right)$ in a three-
\end{abstract}

color assay clearly showed a reduction in the number of such cells in newly diagnosed IMD patients compared with normal controls (Figure 1a). Reduced numbers of NK T cells ( $<0.1 \%$ of $V \alpha 24 / \mathrm{V} \beta 11^{+} \mathrm{T}$ cells) were also evident in 9 of the 12 autoantibody-positive but nondiabetic patients, and in 17 of the 23 long-diagnosed IMD patients. Whereas the type 2 diabetic patients $(n=15)$ had reduced numbers of NK T cells over those of normal controls $(P<0.02)$, the number was significantly more than the newly diagnosed IMD patients $(P<0.04)$. The 26 normal controls had a mean percentage of $\mathrm{CD}^{+} \mathrm{V} \alpha 24^{+} \mathrm{T}$ cells of $0.74 \% \pm 0.06 \%$, whereas that of $\mathrm{CD}^{+} \mathrm{V} \beta 11^{+} \mathrm{T}$ cells was $0.94 \% \pm 0.09 \%$. The mean percentage of $\mathrm{CD}^{+} \mathrm{V} \alpha 24^{+}$in newly diagnosed IMD patients $(n=31)$ was lower at $0.38 \% \pm 0.02 \%(P<0.0001)$. Similarly, $\mathrm{CD} 3^{+} \mathrm{V} \beta 11^{+} \mathrm{T}$ cells were reduced in new-onset IMD at $0.44 \% \pm 0.02 \%(P<0.0001)$. These $\mathrm{T}$ cell numbers were also significantly lower in the long-standing IMD patients, $0.34 \% \pm 0.02 \%(P<0.0001)$ and $0.53 \% \pm 0.03 \%$ $(P<0.001)$ for $\mathrm{CD}^{+} \mathrm{V} \alpha 24^{+}$and $\mathrm{CD}^{+} \mathrm{V} \beta 11^{+}$cells, respectively. Nine of the $12 \mathrm{ICA}^{+}$relatives with additional Ab's (four $\mathrm{GAD}_{65} \mathrm{~A}^{+}$, two IA- $2 \mathrm{~A}^{+}$, and three GAD65A $\mathrm{A}^{+}$plus IA- $2 \mathrm{~A}^{+}$) showed significantly reduced $\mathrm{CD} 3^{+} \mathrm{V} \alpha 24^{+}$cells $(0.53 \pm 0.2, P<0.02)$ when the other three (with normal values) were excluded. This was significant in that all nine of these relatives were at high risk for diabetes themselves, whereas the other three with only one autoantibody had a much lower risk (36). However the entire group of 12 relatives had low numbers of $\mathrm{CD}^{+} \mathrm{V} \beta 11^{+}$cells $(0.59 \pm 0.05, P<0.03)$.

To exclude that we were measuring significant numbers of conventional $\mathrm{T}$ cells that happened to express $\mathrm{V} \alpha 24^{+}$and/or $\mathrm{V} \beta 11^{+} \mathrm{TCR}$, we confirmed our data by using $\mathrm{mAb}(6 \mathrm{~B} 11)$ to the invariant $\mathrm{V} \alpha 24 \mathrm{~J} \alpha \mathrm{Q}$ junction and found nearly identical results (Figure 1, b and c), documenting that the triple-positive T cells (Figure 1a) were essentially all NK T cells.

As an additional confirmation, we next examined CD4-CD8- DN populations obtained from PBMCs from normal controls, IMD, and type 2 diabetic patients for their expressions of the canonical TCR (V $\alpha 24 \mathrm{~J} \alpha \mathrm{Q})$ segment using RT-PCR. After PCR amplification with a set of the V $\alpha 24$ and $C \alpha$ primers, the PCR products were separated by electrophoresis on $2 \%$ agarose gel, and specific bands of approximately $190 \mathrm{bp}$ were detected. The PCR products were blotted onto nylon membranes and were hybridized with $\left[\gamma^{-32} \mathrm{P}\right]$ ATP-labeled oligonucleotide probe specific for $J \alpha Q$. Both normal controls and the IMD patients expressed V $\alpha 24 J \alpha Q$, but the mean level of expression in the patients was reduced approximately fivefold compared with the normal controls (Figure 2a), as determined by quantitative phosphorimaging $(P<0.01)$ (Figure $2 \mathrm{e})$. While the type -2 diabetic patients had lower mean levels of expression of the canonical transcript in the PBMCs as compared with the normal controls $(P<0.05)$, the expression was significantly more than type 1 diabetic patients $(P<0.05)$ (Figure 2c). In total, four controls (all normal) and four type 2 diabetic patients (intermediate expres- 
Table 2

Functional defect of peripheral $\mathrm{CD}^{+} \mathrm{V} \alpha 24^{+}$cells in IMD patients

Groups

Normal controls $(n=5)$

ICA + relatives $(n=5)$

Long-standing diabetics $(n=10) \quad 0.282 \pm 0.04^{\mathrm{A}}$

PBMCs of the patients and normal controls were stimulated with PMA + I and stained for cell surface antigens (CD3 and Vo24) and both Th1 (IFN- $\gamma$ ) and Th2 (IL-4) intracellular cytokines. CD3 ${ }^{+} \mathrm{T}$ cells were gated and analyzed for the expression of $\mathrm{V} \alpha 24$ (to enrich for NKT cells) and IFN- $\gamma$ or IL-4. CD $3^{+} V \alpha 24^{+} T$ cells were significantly defective in secretion of either IFN- $\gamma$ or IL-4 both in newly diagnosed $(P<0.02$ and 0.04$)$ as well as longdiagnosed IMD patients $(P<0.03$ and 0.01$)$ as compared with the controls. AStatistically significant.

sion), plus 15 patients with IMD (all abnormal) were studied. Furthermore, by sequencing the PCR products eluted from the gel, we confirmed that these bands corresponded to the invariant $\mathrm{V} \alpha 24 \mathrm{~J} \alpha \mathrm{Q} T \mathrm{TCR}$, a marker for human NK T cells.

Functional (cytokine) abnormalities of patient $V \alpha 24^{+} T$ cells. We found that NK T cells in normal controls represented approximately one-half of all the $\mathrm{CD}^{+} \mathrm{V} \alpha 24^{+}$ $T$ cells in that they expressed V $\beta 11$ as well as the canonical V $\alpha 24 J \alpha Q$ junction. We studied the V $\alpha 24^{+}$subpopulation of $\mathrm{T}$ cells as highly enriched for NK T cells for their INF- $\gamma$ and IL-4 cytokine expressions in the various patient groups by a three-color FACS assay and found that while the numbers of IFN- $\gamma$ were always more than IL-4-secreting cells, the number secreting either IFN- $\gamma$ or IL-4 cytokines was reduced in both newly diagnosed and long-standing IMD patients, compared with the normal controls (Table 2). Similarly, the ICA-positive but nondiabetic relatives showed reduced IFN- $\gamma$ secretion as compared with the normal controls.

Lack of association of CD1d with buman IMD. Since defective CD1d signaling could lead to defective NK $\mathrm{T}$ cell stimulation, we next compared $\mathrm{CD} 1 \mathrm{~d}$ gene structure in ten diabetic patients and ten controls. We found no mutations or polymorphisms using automated sequencing within the coding region of CD1d gene. While both homozygous and heterozygous substitutions were found at four different positions in the sequences, in the $5^{\prime}$ UTR located in the region of 600-800 base, upstream of the start code of the CD1d gene, they randomly occurred in both the patients and controls, implying that these four substitutions are irrelevant polymorphisms and not disease-significant mutations. Thus we found no genetic evidence for an association of the CD1d gene in the pathogenesis of IMD.

Deficiency of immunoregulatory $\mathrm{CD}^{+} \mathrm{CD} 25^{+} \mathrm{T}$ cells in patients with IMD. We next tested resting $\mathrm{CD}^{+} \mathrm{T}$ cell expression of CD25 (IL-2R- $\alpha$ ) in our patients with type 1 diabetes. Significant deficiencies of these regulatory $\mathrm{T}$ cells were regularly seen in our patients but not in the type 2 diabetics or in the normal controls (Figure 3 ). However, no differences were found in the expression

of CD122 (IL-2R- $\beta$ ) on the resting T cells between patients and controls. This data confirms that this unique regulatory $\mathrm{T}$ cell subset is also deficient in IMD patients as in NOD mice (37). We studied two ICA ${ }^{+}$relatives (one $\mathrm{GAD}_{65} \mathrm{~A}^{+}$plus IA- $2 \mathrm{~A}^{+}$and one $\mathrm{GAD}_{65} \mathrm{~A}^{+}$), and these relatives also had reduced $\mathrm{CD} 4{ }^{+} \mathrm{CD} 25^{+} \mathrm{T}$ cells (mean $3.21 \pm 0.53$ ) as compared with the normal controls $(P<0.001)$.

Intrinsic cytokine defect in IMD patient $T$ cells. NOD mice have been reported to have $T$ cell abnormalities, as have diabetic patients, particularly in their heterogeneous $\mathrm{T}$ cell cytokine responses to different stimuli. We studied the cytokine responses of patient $T$ cells after their stimulation with PMA + I. PMA acts by activating protein kinase $C$ directly while I causes an influx of $\mathrm{Ca}^{2+}$ from the extracellular space into cell cytoplasm. The FACS analysis was carried out in $\mathrm{CD}^{+}$ T cells from 16 newly diagnosed IMD patients, and the cytokine expressed (IFN- $\gamma$ ) was significantly reduced when compared with 21 normal controls studied identically. The number of $\mathrm{CD}^{+} \mathrm{T}$ cells secreting IL-4 was not different when we excluded the two normal control outliers that showed high IL-4 production (Figure 4 , a and b), however the numbers of $\mathrm{CD}^{+} \mathrm{T}$ cells secreting IFN- $\gamma$ were reduced in longstanding IMD patients, while it was the $\mathrm{CD} 4^{+} \mathrm{T}$ cells that were defective in secreting these cytokines (Figure $4, \mathrm{~b}$ and c). Seven autoantibody-positive nondiabetic subjects were also studied for cytokine expression of their $\mathrm{CD}^{+} \mathrm{T}$ lymphocytes after PMA + I stimulation, and three $\mathrm{ICA}^{+}$subjects showed reduced IFN- $\gamma(P<0.01)$ and IL-4 $(P<0.03)$ like the newly diagnosed IMD patients, and two of these three patients were at high risk of impending IMD because of positive $\mathrm{GAD}_{65} \mathrm{~A}$ plus IA-2A (36). The remaining autoantibody-positive subjects (four of seven) showed normal numbers of $\mathrm{T}$ cells secreting IFN- $\gamma$.

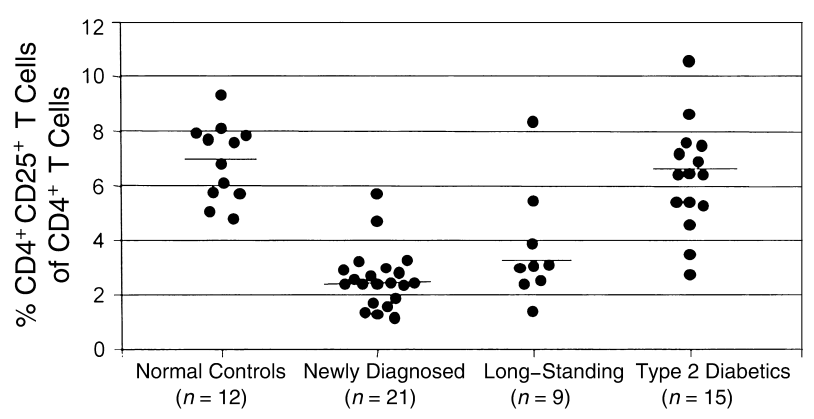

\section{Figure 3}

Deficiency of $C D 4^{+} \mathrm{CD} 25^{+} \mathrm{T}$ cells in IMD patients. Resting PBMCs were stained with mAbs to CD4 and CD25 in a two-color flow cytometry assay and analyzed by flow cytometry. In newly diagnosed IMD as well as long-standing type 1 diabetic patients, the mean percentage of these immunoregulatory cells of $\mathrm{CD} 4{ }^{+} T$ cells was reduced to $2.6 \pm 0.23(P<0.001)$ and $3.7 \pm 0.69(P<0.002)$, respectively, with $6.9 \pm 0.4$ and $6.3 \pm 0.48(P=\mathrm{NS})$ in the normal control and type 2 diabetic groups, respectively. The horizontal line represents the mean of that group. 


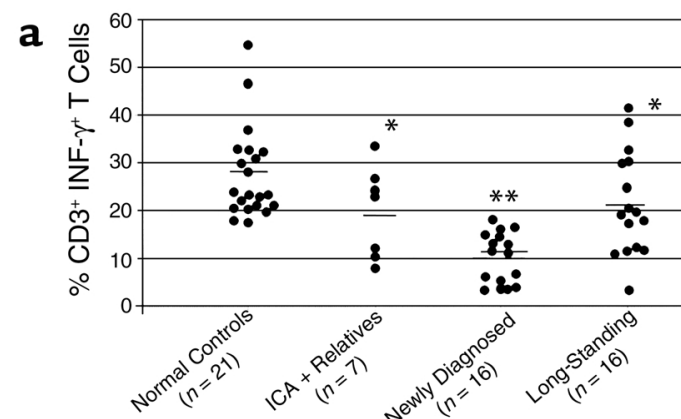

d

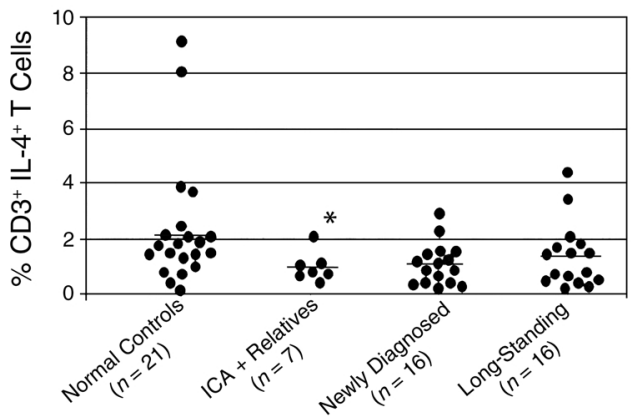

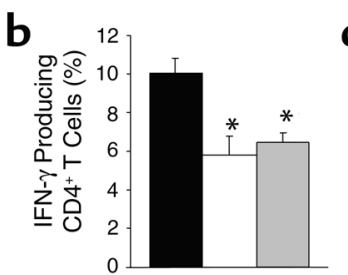
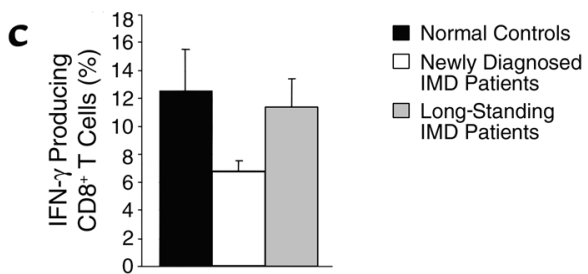

\section{Figure 4}

Defective Th1 cytokine production in IMD patients at various stages of the disease. PBMCs from various groups were stimulated with PMA + I and were analyzed for the cell surface expression of CD3 and intracellular IFN- $\gamma$ and IL-4 cytokines. Each dot represents one subject. (a) This figure depicts IFN- $\gamma$ production in the patient groups. The percentage of T cells secreting IFN- $\gamma$ was significantly reduced in newly diagnosed $(P<0.001)$ and long-standing IMD patients $(P<0.03)$ compared with the normal controls. $\mathrm{CD}^{+} \mathrm{T}$ cells were further characterized into $\mathrm{CD}^{+}(\mathbf{b})$ and $\mathrm{CD}^{+}(\mathbf{c})$ subsets for the cytokine production. $\mathrm{CD} 4^{+} \mathrm{T}$ cells showed significantly reduced IFN- $\gamma$ production in both newly diagnosed $(P<0.003)$ and long-standing IMD patients $(P<0.005)$. Three out of seven ICA ${ }^{+}$ relatives so tested also had reduced numbers of T cells secreting IFN- $\gamma(P<0.01)$, while the other four were in the normal range. (d) Percentage of IL-4-secreting $T$ cells was not reduced in IMD patient groups compared with controls. The horizontal bars represent the mean of that group.

\section{Discussion}

We have identified defects in peripheral Treg cells in IMD patients affecting both the $\mathrm{NK} \mathrm{T}$ and $\mathrm{CD} 4^{+} / \mathrm{CD} 25^{+}$ $T$ cell subsets and a functional abnormality of peripheral blood $\mathrm{T}$ cells manifested by diminished production of Th1 (IFN- $\gamma$ ) cytokine after their in vitro stimulation with PMA + I. All of these abnormalities could be the result of an underlying thymic disorder. While some type 2 diabetic patients also have low levels of NK T cells, but not to the degree found in IMD, their $\mathrm{CD} 4{ }^{+} \mathrm{CD} 25^{+} \mathrm{T}$ cell numbers, however, are normal.

Clonal deletion or anergy of autoreactive $\mathrm{T}$ cells is an important mechanism to obviate autoimmunities, however peripheral $\mathrm{T}$ cell subsets actively contribute to the maintenance of self-tolerance. We found low numbers of NK T cells in prediabetic, newly diagnosed, and long-standing IMD patients alike using extensive flow cytometry methods as verified through RT-PCR analyses. A previous study reported reduced $\mathrm{J} \alpha \mathrm{Q}^{+} \mathrm{TCR}$ transcripts in $\mathrm{T}$ cell clones produced from purified DN T cells that expressed V $\alpha 24^{+} \mathrm{TCR}$ in type 1 diabetic and nondiabetic siblings of IMD patients (nine patients vs. six normal controls) (38). We found two J $\alpha Q$ hybridizing transcript bands in our RT-PCR studies that likely represent the invariant $\mathrm{V} \alpha 24 \mathrm{~J} \alpha \mathrm{Q}$ segment with an alternative sequence (39). We sequenced the lower band from normal controls and found it to correspond to the canonical $V \alpha 24 \mathrm{~J} \alpha \mathrm{Q}$, but could not obtain sufficient PCR product from the IMD patients for sequencing. In line with our data of reduced numbers of NK T cells in IMD presented herein, similar observations have been made in patients with other autoimmune diseases such as systemic sclerosis (27), multiple sclerosis (29), and rheumatoid arthritis (28), suggesting that this defi- ciency predisposes to autoimmunity beyond that restricted to pancreatic islet cells as in IMD. We also found that NK T cells in IMD had functional defects in their abilities to produce cytokines, especially IFN- $\gamma$. A previous report suggested that NK T cell clones developed from patients with type 1 diabetes secreted IFN- $\gamma$ but not IL-4 (38), while NK T cell clones from their identical twins and siblings who were discordant for diabetes secreted IL-4 normally. The implication was that the patients' IL-4-deficient NK T cells might not be able to initiate Th2 responses, but rather only Th1 pathway responses to self by default. Furthermore, it was reported that IL-4-null cells from diabetic patients had significant differences in their expressions of the Th2 cytokine genes including IL-5 (40). Our findings are reminiscent of those in NOD mice where impaired immunoregulation correlated with defective NK T cell proliferation and impaired differentiation toward IFN- $\gamma$ secreting phenotype (26). While NK T cells secrete large amounts of both IFN- $\gamma$ and IL-4 (41), we found diminished levels of both cytokines in NK T cells in IMD. The mechanism by which immunoregulation is mediated by NK T cells is unknown, however they are thought to respond by engagement of their invariant TCR to one or more self glycolipids presented in the context of DCs expressing CD1d (42). Furthermore, CD1d recognition in the thymus, and probably the periphery as well, is a critical signal for maturation of NK T cells $(43,44)$. However, we found no primary defects in the structural CD1 gene or its promotor in our IMD patients, but only nondiabetes-associated polymorphisms in CD1d gene (45). Takahashi et al. previously studied the expression levels of CD1a in peripheral blood DCs of the $\mathrm{ICA}^{+}$and newly diagnosed 
diabetic patients (46) and found them reduced; however, only CD1d presents antigen to NK T cells.

Besides NK T cells, $\mathrm{CD} 4^{+} \mathrm{CD} 25^{+} \mathrm{T}$ cells can prevent the development of autoimmune diseases such as thyroiditis (47), gastritis (48), and diabetes (49) when transferred into experimental animal models. We and others have shown a reduction in this $\mathrm{CD}^{+}$subset in NOD mice $(37,50)$. These resting $\mathrm{CD} 4^{+} \mathrm{CD} 25^{+} \mathrm{T}$ cells represent a unique subset of regulatory $\mathrm{T}$ cells with a highly stable expression of IL-2R $\alpha$ (CD25) in contrast to the transient expression of $\mathrm{CD} 25$ seen on activated $\mathrm{T}$ cells (31). Recently, the existence of $\mathrm{CD} 4^{+} \mathrm{CD} 25^{+} \mathrm{T}$ cells was described in human thymuses and peripheral blood $(34,51)$. These cells proliferate poorly to mitogenic stimulation and suppress the proliferation of $\mathrm{CD} 4^{+} \mathrm{CD} 25^{-} \mathrm{T}$ cells. Whereas we found the $\mathrm{CD} 25^{+}$subset to be deficient in our patients, it remains to be shown that such an immunoregulatory $\mathrm{CD}^{+} \mathrm{T}$ cell population is a functionally and phenotypically homogeneous entity of Treg cells. However, the proportion of these cells that expressed the apoptosis promoting CTLA-4 antigen was similar in patients and controls (data not shown).

While $\mathrm{CD} 4^{+} / \mathrm{CD} 25^{+} \mathrm{T}$ cells were normal in type 2 diabetic patients, some had low numbers of NK T cells. Various studies in genetically obese Wistar fatty rats and obese diabetic mice $(52,53)$, as well as patients with type 2 diabetes (54), have been reported to have impaired cell-mediated immune responses, explaining the increased incidence of infections in these patients. The metabolic glucose disturbance is the probable explanation (55-57). Indeed, our patients in the best diabetes control appeared to have normal numbers of NK T cells. This is consistent with the suggestion of von Kanel et al. (56) that hyperglycemia promotes lymphopenia. Many of our type 2 diabetic patients with low levels of NK T cells were also being treated with PPAR- $\gamma$ agonists when studied, agents that have been recently recognized to be anti-inflammatory (58). It is therefore plausible that these drugs could affect NK T cell levels too.

The role of cytokines in mediating autoimmune diabetes has been extensively studied in NOD mice. Intraislet expression of IFN- $\gamma$ is generally associated with pathology, while IL-4 expression induced experimentally usually blocks the development of the disease $(4,59)$. This imbalance between Th1/Th2 pathways might be a possible mechanism for the exacerbation of the disease, albeit we believe this idea to be overly simplistic. In fact we found no evidence for polarized Th1 over Th2 responses to the strong in vitro stimulus of PMA + I. Reduced IL-4 as well as IFN- $\gamma$ levels in the mRNA expression profiles in the resting PBMCs of newly diagnosed diabetic patients have been reported, in line with our findings (11). Th1 cells are more prone to activation-induced apoptosis than are Th2 cells. Thus their deletion might occur preferentially and spare $\beta$-cell autoreactive $\mathrm{T}$ cells producing Th 2 rather than Th1 cytokines. This could be misinterpreted as a Th1 to Th 2 deviation among $\beta$ cell-infiltrating $\mathrm{T}$ cells of NOD mice protected from overt diabetes by various immunostimulatory treatments such as bacillus, camette, guerin, and CFA (60).

Our findings suggest that there is an underlying global defect in $\mathrm{T}$ cells in IMD leading to immune deficiencies affecting immunoregulation. Others have suggested a global $\mathrm{T}$ cell defect in the disease, too (61). Low T cell IL-2 production was reported in IMD patients that appeared to be related to marked $\beta$ cell destruction (62). Another study found IL-2 and soluble IL-2 receptor secretion defects in both newly diagnosed and longstanding diabetic patients (63). Moreover, a defective thymic $\mathrm{T}$ cell activation to ConA and anti-CD3 has been observed in NOD mice, suggesting a $\mathrm{T}$ cell defect in this animal model as well (64). This T cell hyporesponsiveness correlates with reduced p56 lck that is involved in the $\mathrm{T}$ cell signal transduction pathway as suggested by Nervi et al. (65). Further studies are required to quantify the molecules involved in the $T$ cell signal-transduction pathways in these patients.

In conclusion, we postulate that the dual reductions of peripheral NK T cells and $\mathrm{CD} 4^{+} \mathrm{CD} 25^{+} \mathrm{T}$ cells represent major underlying defects in the $T$ cell regulatory network underlying IMD. We have found identical defects in NOD mice (50) that are severely deficient in NK T cells studied in several tissues by the expression of the invariant Vo14Jo281 TCR transcripts by a quantitative real-time RT-PCR. The dual immunoregulatory defect that we have exposed may be a reflection of a broad $\mathrm{T}$ cell lesion. This could result from an underlying defect in antigen-presenting cells $(66,67)$, albeit a thymic disorder affecting their genesis is equally plausible. Since NK T cells were not absent in our patients, ways to stimulate them should be actively sought to provide novel therapies for the future. At present, $\alpha$-galactosylceramide ( $\alpha \mathrm{GalCer})$ is such an antigen with proven capability to do this, yet this substance is not a normal bodily constituent (only $\beta \mathrm{Gal}-$ Cer is found in mammalian tissues), while an inadvertent deviation toward a Th1 response through use of this agent or its analogues could conceivably worsen rather than help the underlying pathogenic process. Very recent reports of $\alpha \mathrm{GalCer}$ as a preventative in NOD mice have been very encouraging $(68,69)$. Thus the exciting possibility of a therapeutic benefit in patients warrants that such avenues be actively pursued in human trials under the appropriate safeguards in the near future, while bone marrow reconstitutions might come to have a therapeutic place as the risks from the procedure continue to decline.

\section{Acknowledgments}

We thank the many patients who permitted us to study them. This work was supported by NIH grant M01-RR06020, an Innovation Grant (7-01-IN-06) from the American Diabetes Association, and a grant from the Eli Lilly Company. A. Kukreja was supported by a fellowship grant (3-1999-768) from the Juvenile Diabetes Foundation. 
1. Maclaren, N.K., and Kukreja, A. 2000. Type 1 diabetes. In The metabolic and molecular bases of inherited disease, Vol. II. 8th edition. William S. Sly, editor. McGraw-Hill. St. Louis, Missouri, USA. 1471-1488.

2. Abbas, A.K., Murphy, K.M., and Sher, A. 1996. Functional diversity of helper T lymphocytes. Nature. 383:787-793.

3. Rabinovitch, A., Suarez-Pinzon, W.L., Sorensen, O., Bleackley, R.C., and Power, R.F. 1995. IFN-gamma gene expression in pancreatic islet-infiltrating mononuclear cells correlates with autoimmune diabetes in nonobese diabetic mice. J. Immunol. 154:4874-4882.

4. Rabinovitch, A. 1994. Immunoregulatory and cytokine imbalances in the pathogenesis of IDDM. Therapeutic intervention by immunostimulation? Diabetes. 44:859-862.

5. Cameron, M.J., et al. 1997. IL-4 prevents insulitis and insulin-dependent diabetes mellitus in nonobese diabetic mice by potentiation of regulatory T helper-2 cell function. J. Immunol. 159:4686-4692.

6. Foulis, A.K., McGill, M., and Farquharson, M.A. 1991. Insulitis in type 1 (insulin-dependent) diabetes mellitus in man - macrophages, lymphocytes, and interferon-gamma containing cells. J. Pathol. 165:97-103.

7. Huang, X., et al. 1995. Interferon expression in the pancreases of patients with type 1 diabetes. Diabetes. 44:658-664.

8. Hultgren, B., Huang, X., Dybdal, N., and Stewart, T.A. 1996. Genetic absence of gamma-interferon delays but does not prevent diabetes in NOD mice. Diabetes. 45:812-817.

9. Kanagawa, O., Xu, G., Tevaarwerk, A., and Vaupel, B.A. 2000. Protection of nonobese diabetic mice from diabetes by gene(s) closely linked to IFN-gamma receptor loci. J. Immunol. 164:3919-3923.

10. Wogensen, L., Lee, M.S., and Sarvetnick, N. 1994. Production of interleukin 10 by islet cells accelerates immune-mediated destruction of beta cells in nonobese diabetic mice. J. Exp. Med. 179:1379-1384.

11. Halminen, M., Simell, O., Knip, M., and Ilonen, J. 2001. Cytokine expression in unstimulated PBMC of children with type 1 diabetes and subjects positive for diabetes-associated antibodies. Scand. J. Immunol. 53:510-513

12. Lamhamedi-Cherradi, S.E., et al. 1998. Resistance of T-cells to apoptosis in autoimmune diabetic (NOD) mice is increased early in life and is associated with dysregulated expression of Bcl-x. Diabetologia. 41:178-184.

13. Marron, M.P., et al. 1997. Insulin-dependent diabetes mellitus (IDDM) is associated with CTLA4 polymorphisms in multiple ethnic groups. Hum. Mol. Genet. 6:1275-1282.

14. Takeda, K., et al. 1996. Liver NK1.1+CD4+ alpha beta T cells activated by IL-12 as a major effector in inhibition of experimental tumor metastasis. J. Immunol. 16:3366-3373.

15. Cui, J., et al. 1997. Requirement for Valpha14 NKT cells in IL-12-mediated rejection of tumors. Science. 278:1623-1626.

16. Smyth, M., and Godfrey, D. 2000. NKT cells and tumor immunity - a double-edged sword. Nat. Immunol. 1:459-460.

17. Davodeau, F., et al. 1997. Close phenotypic and functional similarities between human and murine alphabeta T cells expressing invariant TCR alpha-chains. J. Immunol. 158:5603-5611.

18. Exley, M., Garcia, J., Balk, S.P., and Porcelli, S. 1997. Requirements for CD1d recognition by human invariant Valpha24+ CD4-CD8- T cells. $J$. Exp. Med. 186:109-20.

19. Porcelli, S., Yockey, C., Brenner, M., and Balk, S. 1993. Analysis of T cell antigen receptor (TCR) expression by human peripheral blood CD4-8[alpha]/[beta] T cells demonstrates preferential use of several V[beta] genes and an invariant TCR [alpha] chain. J. Exp. Med. 178:1-16.

20. Lantz, O., and Bendelac, A. 1994. An invariant T cell receptor alpha chain is used by a unique subset of major histocompatibility complex class I-specific CD4+ and CD4-8- T cells in mice and humans. J. Exp. Med. 180:1097-1106.

21. Hammond, K.J., et al. 1999. NKT cells are phenotypically and functionally diverse. Eur. J. Immunol. 29:3768-3781.

22. Mieza, M.A., et al. 1996. Selective reduction of V alpha 14+ NK T cells associated with disease development in autoimmune-prone mice. $J$. Immunol. 156:4035-4040.

23. Yoshimoto, T., Bendelac, A., Hu-Li, J., and Paul, W.E. 1995. Defective IgE production by SJL mice is linked to the absence of CD4+, NK1.1+ T cells that promptly produce interleukin 4. Proc. Natl. Acad. Sci. USA. 92:11931-11934.

24. Baxter, A.G., Kinder, S.J., Hammond, K.J., Scollay, R., and Godfrey, D.I. 1997. Association between alphabetaTCR+CD4-CD8- T-cell deficiency and IDDM in NOD/Lt mice. Diabetes. 46:572-582.

25. Lehuen, A., et al. 1998. Overexpression of natural killer T cells protects Valpha14- Jalpha281 transgenic nonobese diabetic mice against diabetes. J. Exp. Med. 188:1831-1839.

26. Falcone, M., Yeung, B., Tucker, L., Rodriguez, E., and Sarvetnick, N. 1999. A defect in interleukin 12-induced activation and interferon gamma secretion of peripheral natural killer $T$ cells in nonobese diabetic mice suggests new pathogenic mechanisms for insulin-dependent diabetes mellitus. J. Exp. Med. 190:963-972.

27. Sumida, T., et al. 1995. Selective reduction of T cells bearing invariant V alpha $24 \mathrm{~J}$ alpha $\mathrm{Q}$ antigen receptor in patients with systemic sclerosis. J.
Exp. Med. 182:1163-1168.

28. Yanagihara, Y., Shiozawa, K., Takai, M., Kyogoku, M., and Shiozawa, S. 1999. Natural killer (NK) T cells are significantly decreased in the peripheral blood of patients with rheumatoid arthritis (RA). Clin. Exp. Immunol. 118:131-136.

29. Illes, Z., et al. 2000. Differential expression of NK T cell V[alpha]24J[alpha]Q invariant TCR chain in the lesions of multiple sclerosis and chronic inflammatory demyelinating polyneuropathy. $J$ Immunol. 164:4375-4381.

30. Suri-Payer, E., Amar, A.Z., Thornton, A.M., and Shevach, E.M. 1998. CD4+CD25+ T cells inhibit both the induction and effector function of autoreactive $\mathrm{T}$ cells and represent a unique lineage of immunoregulatory cells. J. Immunol. 160:1212-1218.

31. Kuniyasu, Y., et al. 2000. Naturally anergic and suppressive $\mathrm{CD} 25(+) \mathrm{CD} 4(+) \mathrm{T}$ cells as a functionally and phenotypically distinct immunoregulatory T cell subpopulation. Int. Immunol. 12:1145-1155.

32. Thornton, A.M., and Shevach, E.M. 1998. CD4+CD25+ immunoregulatory $\mathrm{T}$ cells suppress polyclonal $\mathrm{T}$ cell activation in vitro by inhibiting interleukin 2 production. J. Exp. Med. 188:287-296.

33. Sakaguchi, S., Fukuma, K., Kuribayashi, K., and Masuda, T. 1985. Organ specific autoimmune diseases induced in mice by elimination of $\mathrm{T}$ cell subset. I. Evidence for the active participation of possible cause of autoimmune disease. J. Exp. Med. 161:72-87.

34. Stephens, L.A., Mottet, C., Mason, D., and Powrie, F. 2001. Human CD4+CD25+ thymocytes and peripheral T cells have immune suppressive activity in vitro. Eur. J. Immunol. 31:1247-1254.

35. Sonoda, K.H., Exley, M., Snapper, S., Balk, S.P., and Stein-Streilein, J. 1999. CD1-reactive natural killer T cells are required for development of systemic tolerance through an immune-privileged site. J. Exp. Med. 190:1215-1226.

36. Maclaren, N., et al. 1999. Only multiple autoantibodies to islet cells (ICA), insulin, GAD65, IA-2 and IA-2beta predict immune-mediated (type 1) diabetes in relatives. J. Autoimmun. 12:279-287.

37. Salomon, B., et al. 2000. B7/CD28 costimulation is essential for the homeostasis of the CD4+CD25+ immunoregulatory T cells that control autoimmune diabetes. Immunity. 12:431-440.

38. Wilson, S.B., et al. 1998. Extreme Th1 bias of invariant Valpha24JalphaQ T cells in type 1 diabetes. Nature. 391:177-181.

39. Kent, S.C., Hafler, D.A., Strominger, J.L., and Wilson, S.B. 1999. Noncanonical Valpha24JalphaQ $T$ cells with conservative alpha chain CDR3 region amino acid substitutions are restricted by CD1d. Hum. Immunol. 60:1080-1089.

40. Wilson, S.B., et al. 2000. Multiple differences in gene expression in regulatory Valpha24JalphaQ T cells from identical twins discordant for type I diabetes. Proc. Natl. Acad. Sci. USA. 197:7411-7416.

41. Chen, H., and Paul, W.E. 1997. Cultured NK1.1+ CD4+ T cells produce large amounts of IL-4 and IFN-gamma upon activation by anti-CD3 or CD1. J. Immunol.. 159:2240-2249.

42. Liu, Y.-J., Kanzler, H., Soumelis, V., and Gilliet, M. 2001. Dendritic cell lineage, plasticity and cross-regulation. Nat. Immunol. 2:585-589.

43. Bendelac, A. 1995. Positive selection of mouse NK1+ T cells by CD1expressing cortical thymocytes. J. Exp. Med. 182:2091-2096.

44. Adachi, Y., Koseki, H., Zijlstra, M., and Taniguchi, M. 1995. Positive selection of invariant $\mathrm{V}$ alpha $14+\mathrm{T}$ cells by non-major histocompatibility complex-encoded class I-like molecules expressed on bone marrowderived cells. Proc. Natl. Acad. Sci. USA. 92:1200-1204.

45. Han, M., Hannick, L.I., DiBrino, M., and Robinson, M.A. 1999. Polymorphism of human CD1 genes. Tissue Antigens. 54:122-127.

46. Takahashi, K., Honeyman, M.C., and Harrison, L.C. 1998. Impaired yield, phenotype, and function of monocyte-derived dendritic cells in humans at risk for insulin-dependent diabetes. J. Immunol. 161:2629-2635.

47. Sugihara, S., et al. 1988. Autoimmune thyroiditis induced in mice depleted of particular T cell subsets. I. Requirement of Lyt-1 dull L3T4 bright normal T cells for the induction of thyroiditis. J. Immunol. 141:105-113.

48. Smith, H., Lou, Y.-H., Lacy, P., and Tung, K.S.K. 1992. Tolerance mechanism in experimental ovarian and gastric autoimmune diseases. $J$. Immunol. 149:2212-2218.

49. Mordes, J.P., et al. 1987. Transfusions enriched for W3/25+ helper/inducer $\mathrm{T}$ lymphocytes prevent spontaneous diabetes in the BB/W rat. Diabetologia. 30:22-26.

50. Kukreja, A., et al. 2001. Multiple immunoregulatory defects underlie immune mediated (type 1) diabetes in man and mouse. First Annual FOCIS Meeting. Boston, Massachusetts, USA. http://www.clinimmsoc.org.

51. Dieckmann, D., Plottner, H., Berchtold, S., Berger, T.A., and Schuler, G. 2001. Ex vivo isolation and characterization of CD4+CD25+ T cells with regulatory properties from human blood. J. Exp. Med. 193:1303-1310.

52. Tanaka, S., et al. 2000. T lymphopenia in genetically obese-diabetic Wistar fatty rats: effects of body weight reduction on T cells. Metabolism 49:1261-1266.

53. Kimura, M., et al. 1998. T lymphopenia in obese diabetic $(d b / d b)$ mice is non-selective and thymus independent. Life Science. 62:1243-1250.

54. Chang, F.Y., and Shaio, M.F. 1995. Decreased cell-mediated immunity 
in patients with non-insulin-dependent diabetes mellitus. Diabetes Res. Clin. Pract. 28:137-146.

55. Bouter, K.P., et al. 1992. Influence of blood glucose levels on peripheral lymphocytes in patients with diabetes mellitus. Am. J. Clin. Pathol. 19:77-80.

56. von Kanel, R., Mills, P.J., and Dimsdale, J.E. 2001. Short-term hyperglycemia induces lymphopenia and lymphocyte subset redistribution. Life Science. 69:255-262.

57. Spooren, P.F., Vermes, I., and Soons, J.W. 1993. Similar alterations of lymphocyte subpopulations in type 1 and type 2 diabetes. Neth. J. Med. 42:163-167.

58. Harris, S.G., and Phipps, R.P. 2001. The nuclear receptor PPAR gamma is expressed by mouse T lymphocytes and PPAR gamma agonists induce apoptosis. Eur. J. Immunol. 31:1098-1105.

59. King, C., and Sarvetnick, N. 1997. Organ-specific autoimmunity. Curr. Opin. Immunol. 9:863-871.

60. Serreze, D.V., et al. 2001. Th1 to Th2 cytokine shifts in non obese diabetic mice: sometimes an outcome, rather than the cause of diabetes resistance elicited by immunostimulation. J. Immunol. 166:1352-1359.

61. Giordano, C., et al. 1988. Dissociated production of interleukin-2 and immune gamma-interferon by phytohaemoagglutinin stimulated peripheral mononuclear cells in type 1 (insulin-dependent) diabetes. J. Clin. Lab. Immunol. 27:73-76.
62. Kaye, W.A., et al. 1986. Acquired defect in IL-2 production in patients with type 1 diabetes mellitus. N. Engl. J. Med. 315:920-924.

63. Giordano, C., et al. 1989. Interleukin 2 and soluble interleukin 2 receptor secretion defect in vitro in newly diagnosed type 1 diabetic patients. Diabetes. 38:310-315.

64. Zipris, D., Lazarus, A.H., Crow, A.R., Hadzija, M., and Delovitch, T.L. 1991. Defective thymic T cell activation by concanavalin A and antiCD3 in autoimmune nonobese diabetic mice. J. Immunol. 146:3763-3771.

65. Nervi, S., et al. 2000. Specific deficiency of p56[lck] expression in T lymphocytes form type 1 diabetic patients. J. Immunol. 165:5874-5883.

66. Strid, J., et al. 2001. A defect in bone marrow derived dendritic cell maturation in the nonobese diabetic mouse. Clin. Exp. Immunol. 123:375-381.

67. Piganelli, J.D., Martin, T., and Haskins, K. 1998. Splenic macrophages from the NOD mouse are defective in the ability to present antigen. Diabetes. 47:1212-1218.

68. Sharif, S., et al. 2001. Activation of NKT cells by $\alpha$-galactosylceramide treatment prevents the onset and reoccurrence of autoimmune type 1 diabetes. Nat. Med. 7:1057-1062.

69 . Hong, S., et al. 2001. The natural killer T-cell ligand $\alpha$-galactosylceramide prevents autoimmune diabetes in non-obese diabetic mice. Nat. Med. 7:1052-1056. 